\title{
TEORIAS DE RESTAURAÇÃO E ATUAÇÃO EM RUÍNAS ARQUITETÔNICAS: A ESPECIFICIDADE DE PRESIDENTE PRUDENTE - SP.
}

Fabrícia Dias da Cunha de Moraes Fernandes Borges, Jéssica Santos de Souza, Jéssica Tiemi Saito, Mariana Maia da Cruz Fernandes, Raísa de Lacerda Costa

Universidade do Oeste Paulista - UNOESTE. Curso de Arquitetura e Urbanismo, Presidente Prudente - SP. E-mail: marianamaia cf@hotmail.com

\section{RESUMO}

Ao se intervir em sítios históricos muitas vezes o profissional se depara com as chamadas ruínas. Geralmente pouco compreendidas em seu significado, a palavra ruína é comumente empregada como forma de definir edificações velhas e abandonadas, sem uso e depredadas pelo tempo. Mas, afinal, o que é uma ruína? Este artigo trata da ruína como parte do campo disciplinar da Conservação e do Restauro, onde é tema recorrente no campo de atuação projetual e assunto debatido por diversos teóricos em diferentes épocas, tais como, John Ruskin, Viollet Le Duc, Camillo Boito e Cesare Brandi. Através da pesquisa pretende-se trazer uma definição à questão da ruína e, assim, possibilitar a identificação e catalogação de certo número de estratégias projetuais de intervenção realizadas na atualidade no Brasil e no mundo por profissionais que se deparam com este tópico. Além disso, está incluído realizar mapeamento em Presidente Prudente de edificações no que tange ao conceito de ruína.

Palavras-chave: ruínas, estratégias de intervenção, teoria da conservação e restauro

\section{THEORIES OF RESTORATION AND PERFORMANCE IN ARCHITECTURAL RUINS: SPECIFICITY OF PRESIDENTE PRUDENTE - SP.}

\begin{abstract}
When intervening in historical sites often professional is faced with calls ruins. Generally poorly understood in its meaning, the word ruin is commonly employed as a means of defining old buildings and abandoned, unused and vandalized by time. But, after all, what is a ruin? This article deals with the destruction as part of the disciplinary field of Conservation and Restoration, which is a recurring theme in the field of design and performance issue debated by various theorists in different eras, such as John Ruskin, Viollet Le Duc, Camillo Boito and Cesare Brandi . Through research we intend to bring a resolution to the issue of ruin and thus enable the identification and cataloging of a number of intervention strategies projetuais held today in Brazil and worldwide by professionals who encounter this topic. Additionally, is included in President Prudente perform mapping of buildings in relation to the concept of ruin.
\end{abstract}

Keywords: ruins, strategies for intervention, theory of conservation and restoration 


\section{INTRODUÇÃO E JUSTIFICATIVA}

Presidente Prudente, interior do estado de São Paulo, possui um vasto legado de edifícios históricos. Formado por volta de 1921 por meio da iniciativa dos coronéis Goulart e Marcondes, o município se expandiu a partir da implantação da Estrada de Ferro Sorocabana, contudo a malha urbana, ao longo dos anos, obteve maior crescimento espacial na porção oeste devido á questões socioeconômicas.

Segundo Abreu (1972) o desenvolvimento do município é basicamente associado á produção agrícola e, posteriormente, á chegada das indústrias de beneficiamento por volta de 1940. Deste modo, o processo de industrialização do município serviu de impulso para a expansão urbana, vendo que tais indústrias localizavam-se estrategicamente ás margens da Estrada de Ferro Sorocabana, sendo as maiores geradoras de emprego para Presidente Prudente e região fazendo com que diversas famílias, incluindo imigrantes japoneses, fossem atraídas para o município e por consequência se estabelecendo na nova malha urbana.

No decorrer dos anos, novas atividades começaram a ser desenvolvidas no município, descentralizando assim a economia. Assim, diversas indústrias de beneficiamento agrícola e edifícios industriais que foram fundamentais para o desenvolvimento da cidade, se viram obrigados a fechar as portas por volta de 1970, assim como edifícios que serviam de apoio para tais indústrias.

Tais edifícios atualmente pertencem á iniciativa privada, onde a forte especulação imobiliária presente no município agrave o fator de desuso destes edifícios e acelere o processo de ruína arquitetônica dos mesmos. Alguns destes remanescentes inclusive foram vítimas desta problemática, e foram demolidos graças ao descaso do Poder Público Municipal, segundo Hirao; Floeter (2013).

A tipologia destes edifícios é diversificada, passando desde arquiteturas modestas nos edifícios industriais, por obter essa configuração desprendida de convenções estéticas, até edifícios ecléticos no caso do Antigo Hotel Municipal.

O presente artigo apresenta um mapeamento de alguns edifícios nesta condição de ruína arquitetônica, buscando através dos teóricos Ruskin (2008), Viollet-Le-Duc (2006), Boito (2008), Aloïs Riegl (1999), Cesare Brandi (2004) e Kuhl (2009), e referenciais arquitetônicos como: Parque das Ruínas, Conjunto KKKK e Usina Termoelétrica do Gasômetrocomo instrumento para traçar estratégias para atuar efetivamente no tratamento destas ruínas no intuito de preservar a importância histórica que eles representam para o município. Desta forma, apresentar-se-á os edifícios industriais: Sociedade Algodoeira do Nordeste Brasileiro (SANBRA); Anderson\&Clayton; 
Indústrias Reunidas Matarazzo (IRF MATARAZZO); o antigo Expurgo Municipal, recentemente demolido; Indústria de Bebidas Funada e Filhos, também recentemente demolido. E os edifícios do Antigo Hotel Municipal e da Associação Cultural, Agrícola e Esportiva (ACAE- CENTRO), demolida parcialmente.

\section{CONCEITO DE RUÍNA}

Ruskin (2008), precursor de estudos realizados sobre ruína é considerado romântico ao afirmar que arquitetura faz parte da natureza. Defende a pátina e a idade da arquitetura, é classificado como o teórico do anti restauro, descrevendo-o assim: "Não falemos, pois, de restauração. Trata-se de uma Mentira do começo ao fim." (RUSKIN, 2008, p. 81). Complementa que sobre uma ruína tudo deve ser feito, segurá-la com tirantes ou apoiá-la com escoras, sem se importar com a aparência destes, importando somente suportar a ruína até o seu dia fatal. Eugène Emmanuel Viollet-Le-Duc (2006) defende o estado de inteireza que os monumentos devem apresentar. "Restaurar um edifício não é mantê-lo, repará-lo ou refazê-lo, é restabelecê-lo em um estado completo que pode não ter existido nunca em um dado momento." (VIOLLET-LE-DUC, 2006, p. 29). Diz que quando uma parte do monumento é retirada ou substituída, esta deve ser trocada somente por materiais melhores e por meios mais eficazes que os anteriores.

Camillo Boito (2008), apresenta uma crítica à teoria de Le-Duc: "Essa teoria é cheia de perigos. Com ela não existe doutrina, não existe engenho que sejam capazes de nos salvar dos arbítrios: e o arbítrio é uma mentira, uma falsificação do antigo, uma armadilha posta aos vindouros." (BOITO, 2008, p. 58). Afirmando que é necessário fazer de tudo para se conservar um monumento e também, que quando os complementos são indispensáveis devem se mostrar atuais. Aloïs Riegl (1999) classifica os monumentos em diferentes valores, diz que o culto moderno aos monumentos não deve ficar restrito à conservação dos monumentos históricos, devendo também ter respeito e consideração aos monumentos antigos. Assim classifica os monumentos: valor de antiguidade, valor histórico, valor artístico, valor de novidade e valor artístico relativo.

Cesare Brandi (2004) teve como seu principal precursor Aloïs Riegl, tomando os valores histórico e artístico e dissertando acerca deles com um novo título, instância da historicidade e instância estética. Sobre o restauro diz: “[...] a restauração deve visar ao restabelecimento da unidade potencial da obra de arte, desde que isso seja possível sem cometer um falso artístico ou um falso histórico, e sem cancelar nenhum traço da passagem da obra de arte no tempo." (BRANDI, 2004, p. 33). 
Beatriz Kuhl (2009) traz realidade vivenciada atualmente em escala nacional com relação a monumentos industriais. Observando a falta de respeito a estas construções quando referentes às teorias de Brandi e Boito.

Desta forma, as teorias antigas juntamente à realidade vivenciada pelos remanescentes industriais no Brasil, apresentam embasamento teórico para traçar estratégias para uma adequada restauração e até mesmo indícios para uma intervenção respeitosa e ao mesmo tempo autêntica.

\section{EDIFÍCIOS HISTÓRICOS EM RUÍNAS EM PRESIDENTE PRUDENTE}

O mapa abaixo refere-se ao mapeamento realizado em Presidente Prudente, demonstrando a setorização dos edifícios estudados inseridos na malha urbana.

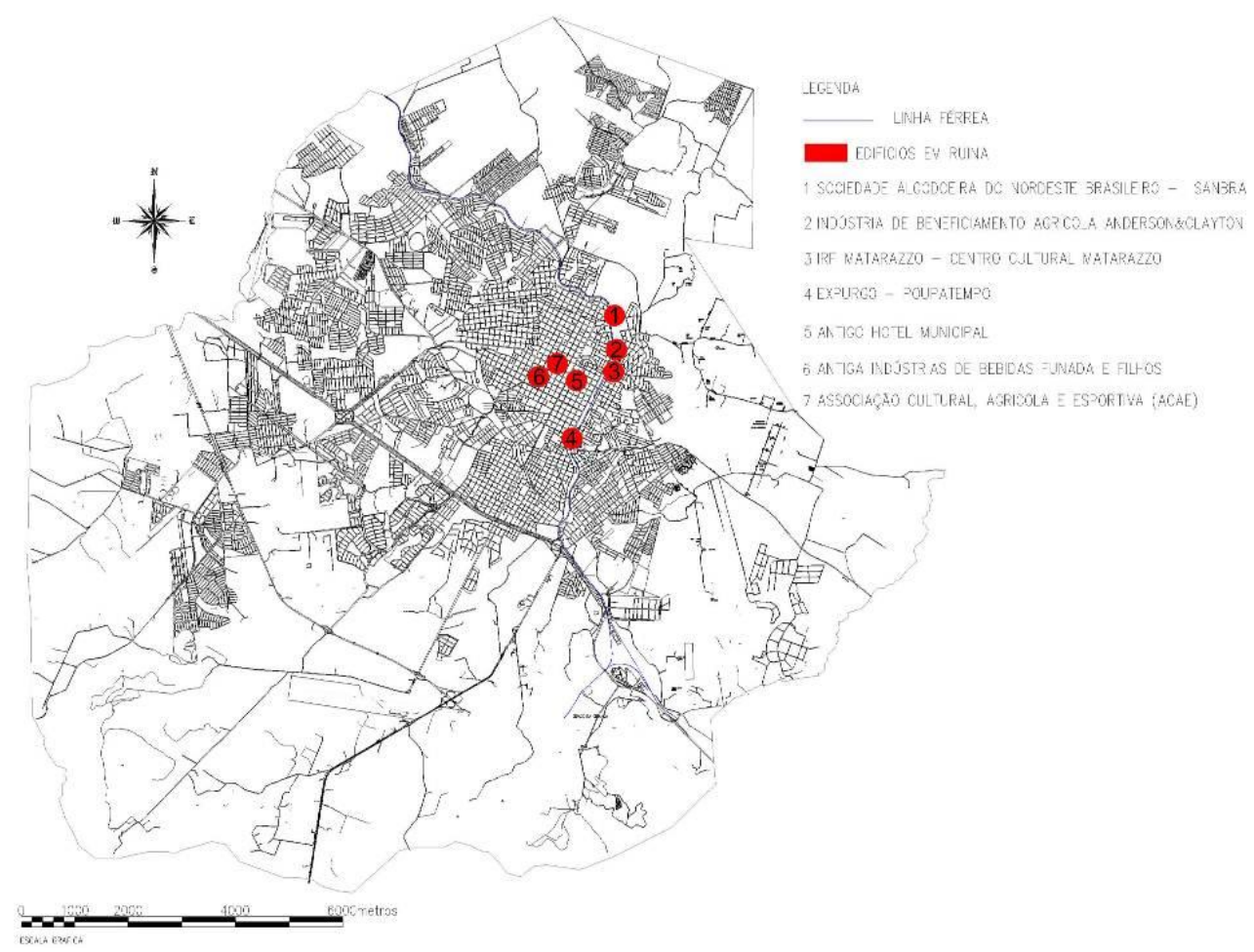

FIGURA 1. Mapeamento dos principais edifícios históricos em ruínas em Presidente Prudente - SP Fonte: Autoras 2014, com base no mapa da Prefeitura Municipal de Presidente Prudente.

A SANBRA chegou ao município por volta de 1940, era uma empresa de beneficiamento agrícola "especializada na compra, beneficiamento e exportação de algodão" (SERRA; FERREIRA 2008, p. 18), atuante em diversos estados brasileiros e, como vimos anteriormente, em países da América Latina, contudo atualmente sofreu uma demolição parcial de seu complexo industrial em prol da implantação de dois condomínios voltados para classe média. 
Segundo o jornal IFronteira (2014) com o declínio das atividades agrícolas em 1960, causando o enfraquecimento e a saída dessas grandes indústrias de beneficiamento, como foi o caso da SANBRA, foi o principal motivo para que a área perdesse o interesse para a população.

Segundo a promotoria de Justiça, "tanto a chaminé quanto os galpões que compõem o conjunto de bens culturais a serem preservados estão á própria sorte há tempos". "A pouca vontade em preservar tais bens está comprovada documentalmente no presente procedimento, visto que tanto o proprietário da área, quanto o Poder Público municipal, que se mostraram indiferentes frente à relevância histórica de tais bens". (IFronteira, 2014, www.ifronteira.com/noticiapresidenteprudente-55755)

De modo particular a IRF Matarazzo, segundo SOUSA (2008) "atuou na cidade até os anos de 1970" trazendo como consequência de seu fechamento "severos danos socioeconômicos", Anos de briga judicial entre propriedade privada e a prefeitura municipal em prol do tombamento e obtenção do espaço para que o edifício se tornasse sede do Centro Cultural Matarazzo, inaugurado em 2008. Observa-se certo respeito à autenticidade neste edifício, pelo fato da intervenção diferenciar o antigo e o novo.

O edifício do Expurgo Municipal que cedeu lugar ao edifício sede do Poupatempo no município, caso este também vivenciado pelo edifício da Indústria de Bebidas Funada e Filho que em 2014 foi completamente demolido. Segundo Shikasho (2012), como muitos imigrantes japoneses que iniciaram a sua trajetória como colonos no Brasil, os fundadores da fábrica iniciam sua carreira de negócios, em 1942, mudando as suas atividades da zona rural para urbana. "Em 15 de setembro de 1947, abrem as portas para uma das maiores fábricas do Brasil. Com o objetivo de crescimento no país, foram além, expandindo sua comercialização para o Paraguai, Bolívia e Japão." (SHIKASHO; EMIKA 2012, p. 296). A fábrica recebeu uma nova sede em outra localidade do município, devido ao crescimento da produção, e a sua antiga sede, ainda assim pertencente à família Funada foi abandonada e devido seu desuso converteu- se em uma ruína arquitetônica.

O Antigo Hotel Municipal foi submetido a uma reforma em 1990, entretanto sua construção foi embargada após a destruição de sua fachada principal e atualmente está em processo de degradação. Segundo Florindo (2013), O edifício do antigo Hotel Municipal a princípio foi construído para o funcionamento de um segundo hospital na cidade, em seguida um sanatório e por fim um hotel.

Localizado em uma região privilegiada, diversas pessoas usufruíram deste edifício, "diante disso, aquele edifício guarda boas histórias em seus corredores e na memória de quem viveu naquela magnífica época". (FLORINDO, 2013 apud RESENDE, 2006). 
De acordo com Florindo (2013, apud Bernad, 2011), este edifício foi parcialmente destruído após a hipótese tombamento, que não foi concluído, por iniciativa de seus proprietários.

Em 1928, os edifícios da Associação Cultural Esportiva e Agrícola (ACAE - CENTRO) foram construídos para criar uma espécie de "ponto de apoio" dentro do perímetro urbano para as 3700 famílias japonesas que residiam e trabalhavam em áreas rurais cuidando da lavoura de algodão, café e hortelã.

A ACAE teve o seu início com a construção do pensionato para estudantes da nossa colônia e do campo de beisebol, que foram escavados com inchada e a terra carregada por duas pessoas em sacos arrastados para o nivelamento (SHICASHO, 2012, pg.37).

Recentemente a Associação contou com a demolição de dois edifícios históricos de 1920, para ceder lugar á uma franquia de fast-food. A questão de tombamento foi levantada, mas sem obtenção de sucesso.

\section{CONCLUSÃO}

Com base nas teorias de restauro apresentadas e com as análises dos referenciais arquitetônicos Conclui-se que, mesmo tendo objetos de estudos com tipologias diversificadas, a melhor maneira de se restaurar um bem imóvel é aquela que o dá um novo uso, sempre prezando pela participação da sociedade levando em consideração a autenticidade de Brandi, sem excluir detalhes da construção que muitas vezes merecem ser deixadas intactas como diz Ruskin, ou clama por um restauro completo como diz Le-Duc.

O novo uso cultural dado à Matarazzo atingiu o objetivo de atrair a sociedade, e tentou prezar o máximo por sua autenticidade. No entanto, se estudos mais profundos tivessem sido realizados anteriormente à intervenção, esta poderia apresentar uma caracterização arquitetônica diferenciada, mostrando ainda mais a realidade do real funcionamento do edifício antigo industrial.

No caso da SANBRA, sua característica arquitetônica modesta deve ser mantida e até mesmo enaltecida para que se faça jus a uma adequada autenticidade. Aos edifícios que foram completamente demolidos, sugere-se uma ficha de inventário pública com fotos e descrições para salientar que um dia existiu um determinado edifício de extrema importância para o desenvolvimento municipal, como sugere Brandi (2004). 
Deste modo, demonstra-se a real possibilidade de se preservar os bens culturais existentes, até mesmo aqueles que se encontram na total degradação de uma ruína, sendo somente necessário atuar com respaldo teórico para sustentar sua história e sua integridade física.

\section{REFERÊNCIAS}

ABREU, Dióres Santos. Formação histórica de uma cidade pioneira paulista: Presidente Prudente. Presidente Prudente: Faculdade de Filosofia, Ciências e Letras de Presidente Prudente, 1972.

ARAÚJO, Jair Barbosa. Breve Histórico Acerca da Representação do Algodão no Desenvolvimento da Cidade de Campina Campina Grande - PB. 2004.

BOITO, C. Os Restauradores. 3 ed. Cotia: Ateliê Editorial, 2008.

BRANDI, C. Teoria da restauração. 1 ed. Cotia: Ateliê Editorial, 2004.

FLORINDO, Camila. Preexistência Arquitetônica Do Saber Contemporâneo: Biblioteca Pública No Edifício Do Antigo Hotel Municipal Em Presidente Prudente.-SP. 2013.

HIRAO, Hélio; FLOETER, Roberto A. O Patrimônio Arquitetônico e Urbanístico de Presidente Prudente: o possível preservado. Revista Tópos, v. 6, n. 2, p. 53-68, 2013.

IFRONTEIRA. Promotoria de Justiça pede preservação de chaminé e galpões da Sanbra. iFronteira, Presidente Prudente, 12 fev. 2014. Disponível em: < http://www.ifronteira.com/noticiapresidenteprudente-55755>. Acesso em: 12 fev. 2014.

IMPARCIAL, O. Mudanças no IBC são essenciais para garantir a tradição de diversos eventos. 0 Imparcial, Presidente Prudente, 09 jun. 2013. Disponível em: < http://www.imparcial.com.br/site/mudancas-no-ibc-sao-essenciais-para-garantir-a-tradicao-dediversos-eventos>. Acesso em: 27 mar. 2014.

KÜHL, Beatriz Mugayar. Preservação do patrimônio arquitetônico da industrialização: problemas teóricos de restauro. Atelie Editorial, 2009.

MASSUDA, Ely Mitite. Produção e consumo de algodão e as indústrias de fiações de algodão no Paraná. Acta Scientiarum. Human and Social Sciences, v. 27, n. 1, p. 61-68, 2005.

RIEGL, A. El Culto Moderno a los Monumentos. 2 ed. Madrid: Gráfica Rógar S.A., 1999.

RUSKIN, J. A Lâmpada da Memória. Cotia: Ateliê Editorial, 2008.

SERRA, Fernando Ribeiro; FERREIRA, Manuel Portugal; CONTRIGIANE, Evandro. 0 turnaround da Bunge nos anos 90. 2008.

SOUSA, Adriano Amaro de. O Processo de Industrialização em São Paulo e o seu Desdobramento no Oeste Paulista: o caso das indústrias de Marília/SP e de Presidente Prudente/SP. ETICENCONTRO DE INICIAÇÃO CIENTÍFICA-ISSN 21-76-8498, v. 3, n. 3, 2009. 
SHIKASHO, Emika. A saga dos imigrantes japoneses em Presidente Prudente. 1ed. Presidente Prudente, 2012.

VICHNEWSKI, Henrique Telles. As indústrias Matarazzo no interior paulista: arquitetura fabril e patrimônio industrial (1920-1960). 2004.

VIOLLET-LE-DUC, E. E. Restauração. 3 ed. Cotia: Ateliê Editorial, 2006. 